Check for updates

Cite this: RSC Adv., 2017, 7, 33467

Received 16th June 2017

Accepted 24th June 2017

DOI: $10.1039 / \mathrm{c} 7 \mathrm{ra0} 6741 \mathrm{k}$

rsc.li/rsc-advances

\title{
Size of the rare-earth ions: a key factor in phase tuning and morphology control of binary and ternary rare-earth fluoride materials $\uparrow$
}

\author{
Pushpal Ghosh, (D) *a Rahul Kumar Sharma, ${ }^{\text {a }}$ Yogendra Nath Chouryal ${ }^{a}$ \\ and Anja-Verena Mudring (D) $\hbar^{* b c}$
}

In an ionic liquid assisted solvothermal synthesis developed by us for the synthesis of rare-earth (RE) fluorides, it is possible to control the product formation by the choice of the rare earth ion. For rareearth cations with smaller ionic radii (below $1.075 \AA$ ), cubic $\mathrm{NaREF}_{4}$ with a spherical morphology is obtained, whilst for rare-earth cations with radii between $1.08 \AA$ and $1.13 \AA$, the formation of hexagonal $\mathrm{NaREF}_{4}$ with a nanorod-like morphology is observed. For rare earth ions with a larger radius than that of $\mathrm{La}^{3+}(1.216 \AA)$, instead of ternary fluorides, binary fluorides $\mathrm{REF}_{3}$ in the trigonal modification is obtained. The growth mechanism behind this morphology change is explained from atomistic origin using electron microscope studies. The lattice strain changes with the rare-earth fluoride phase. For cubic $\mathrm{NaREF}_{4}$ a tensile strain is observed, whilst for the hexagonal and trigonal binary fluoride a compressive strain is observed. The optical properties of the obtained materials promises use for various optoelectronic applications.

\section{Introduction}

Over the last decade rare-earth (RE) ion doped materials have drawn tremendous attention in the field of photonic and biophotonic applications. ${ }^{1-10}$ With respect to their narrow emission bands, large Stokes shifts, weak autofluorescence and decay times typically in the range of milliseconds, RE-doped materials in certain respects are superior to organic dyes and semiconductors. ${ }^{11,12} \mathrm{~A}$ judicious choice of the host and dopant ion/ ion pairs is a precondition to obtain the desired optical materials. ${ }^{1}$ The main criteria in the choice of a suitable host matrix are a low phonon energy, a high refractive index and easy incorporation of dopants together with chemical and thermal stability. ${ }^{13}$ Based on these criteria, binary and ternary fluorides appear to be effective host materials for $\mathrm{RE}^{3+}$ ion doping. ${ }^{14-22}$ For rare-earth trifluorides, $\mathrm{REF}_{3}$, two polymorphs are known. Their relative stability depends on the rare earth ionic radius and temperature. For the lighter $\mathrm{REF}_{3}(\mathrm{RE}=\mathrm{La}-\mathrm{Nd})$ with larger ionic radius the trigonal tysonite type of structure $\left(\mathrm{LaF}_{3}, P \overline{3} c 1\right)$ is

${ }^{a}$ School of Chemical Science and Technology, Department of Chemistry, Dr H. S. Gour University (A Central University), Sagar-470003, Madhya Pradesh, India. E-mail: pushpalghosh27@gmail.com

${ }^{b}$ Department of Materials Science and Engineering, Iowa State University, Ames, IA 50014, USA.E-mail: mudring@iastate.edu

'The Critical Materials Institute, Ames Laboratory, Ames, IA, 50011, USA

$\dagger$ Electronic supplementary information (ESI) available. See DOI: 10.1039/c7ra06741k

$\$$ Fellow of Royal Society of Chemistry (FRSC). the stable form, whilst for the heavier $\mathrm{REF}_{3}$ with smaller $\mathrm{RE}^{3+}$ (Dy-Lu, Y, $\mathrm{YF}_{3}$ type) and the orthorhombic $\beta-\mathrm{YF}_{3}$ (Pnma) is the preferred structure. $\mathrm{REF}_{3}$ with $\mathrm{RE}^{3+}$ ions that have a size in between are dimorphic with the orthorhombic form being the room temperature stable phase and the tysonite structure being the high temperature phase. ${ }^{23-25}$ Similarly, sodium ternary rare earth fluorides are known to form two polymorphs: a cubic phase and a hexagonal phase. ${ }^{26}$ Whilst classical high temperature synthesis methods typically lead to the thermodynamically stable form, on the nanoscale by a judicious choice of the reaction conditions, it is possible to selectively obtain the less stable form. For nanomaterials, it is possible to tune the crystal phase by variation of the reaction conditions, such as temperature, $\mathrm{pH}$ of the reaction, $\mathrm{Ln}^{3+} / \mathrm{F}^{-}$ratio, addition of a surfactant or capping agent, calcination temperature etc. ${ }^{27-30}$ Recently a strategy for phase tuning that relies on ion doping has been developed for $\mathrm{NaREF}_{4}$ NCs (nanocrystals). ${ }^{31-33}$ For optical materials, either the trigonal $\mathrm{REF}_{3}$ form or, even more, the hexagonal modification of $\mathrm{NaREF}_{4}$ is the researcher's choice due to the higher luminescence efficiency. A wide number of $\mathrm{NaREF}_{4}$ materials doped with various $\mathrm{RE}^{3+}$ ions as up and down converting materials have been reported..$^{34-42}$ By tuning the crystal phase of the host materials, the luminescence dynamics of the RE ion can be tuned..$^{14,18,26,29}$ Similarly morphology is an important parameter to tune the luminescence dynamics as illustrated by Mai et al. which had prepared sodium europium fluoride nanospheres, nanopolyhedra and nanorods and compared their fluorescence emission spectra on the basis of different morphologies. ${ }^{37}$ Similar morphology dependent 


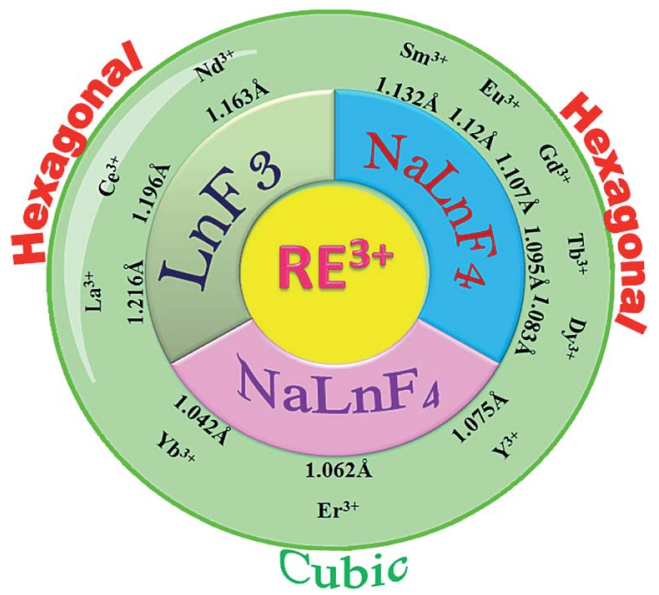

Scheme 1 Tuning of crystal phase and nature of product (binary/ ternary) depending on the size of the $\mathrm{RE}^{3+}$ ions for RE-doped $\mathrm{NaREF}_{4}$.

studies have been reported for other rare-earth doped materials. ${ }^{43-46}$

In this article we report the phase and morphology selective synthesis of rare earth doped binary and ternary rare-earth fluorides employing an ionic liquid (IL) assisted solvothermal method. 1-ethyl-3-methyl imidazolium bromide $\left(\mathrm{C}_{2} \mathrm{mimBr}\right)$ is used as the structure controlling agent. The $\mathrm{RE}^{3+} / \mathrm{F}^{-}$ratio is taken as $1: 8$ in all the cases. Depending on the ionic radius of the chosen host $\mathrm{RE}^{3+}$ ion, a different $\mathrm{NaREF}_{4}$ polymorph for a given $\mathrm{RE}$ or even only formation of the binary $\mathrm{REF}_{3}$ is observed. For example, in the ionic radius range of $1.075 \AA$ to $1.042 \AA$, cubic $\mathrm{NaREF}_{4}$ particles with sphere-like morphology are obtained (Scheme 1). ${ }^{47}$ However, for $\mathrm{RE}^{\prime{ }^{3+}}$ ions with larger ionic radius in the range of 1.13 to $1.095 \AA$ (for $\mathrm{Sm}^{3+}$ to $\mathrm{Tb}^{3+}$ ), hexagonal sodium ternary fluoride with nanorod-like morphology is obtained. A drastic change occurs when a $\mathrm{RE}^{\prime \prime 3+}$ ion with quite a large radius is chosen like $\mathrm{La}^{3+}(1.216$ $\AA)$. Instead of a ternary fluoride, the binary fluoride with hexagon like morphology is obtained (Scheme 1). Normally phase transition and morphology control of nanomaterials need at least one of the following changes: heating at high temperature, change of the reaction parameters like reactant ratio, $\mathrm{pH}$ etc. and other external influences. ${ }^{48-52}$ This type of tuning of the crystal phase, lattice strain, morphology and most importantly nature of the product depending on the ionic radius or size of the $\mathrm{RE}^{3+}$ ion is novel and not reported earlier to the best of our knowledge.

\section{Experimental}

\subsection{Synthesis}

2.1.1 1-Ethyl-3 methyl imidazolium bromide $\left[\mathrm{C}_{2} \mathrm{mim}\right] \mathrm{Br}$. Modifying a literature procedure, $58 \mathrm{ml}$ of ethyl bromide (0.79 mol, Sigma Aldrich 98\%) and $48 \mathrm{ml}$ of $\mathrm{N}$-methyl imidazole (0.607 mol, Sigma Aldrich 99\%) were heated under reflux under inert gas (Ar) atmosphere at $40{ }^{\circ} \mathrm{C}$ for 3 hours in a round bottom flask $(250 \mathrm{ml}) .{ }^{49}$ After cooling to room temperature, ethyl acetate was added and the product crushed out of the solution. After filtration, the crude product was washed with ethyl acetate and dried under vacuum at $25{ }^{\circ} \mathrm{C}$ for 10 hours to give a white solid.

2.1.2 $\mathrm{NaYF}_{4}:$ Eu nanoparticles. In a typical synthesis, $10 \mathrm{ml}$ aqueous solutions of $0.265 \mathrm{M} \mathrm{NaCl}$ (J. T. Baker) and (0.265 M) $\mathrm{Y}\left(\mathrm{NO}_{3}\right)_{3} \cdot 6 \mathrm{H}_{2} \mathrm{O}$ (Alfa Aesar) and the required amount of an aqueous solution of $\mathrm{Eu}\left(\mathrm{NO}_{3}\right)_{3} \cdot 6 \mathrm{H}_{2} \mathrm{O}(99.9 \%$, Alfa Aesar) to give $\mathrm{NaYF}_{4}: 1 \mathrm{~mol} \%$ Eu were added to $60 \mathrm{ml}$ ethanol containing a $20 \mathrm{ml}$ aqueous $5 \mathrm{wt} \%\left[\mathrm{C}_{2} \mathrm{mim}\right] \mathrm{Br}$ solution. To the well-stirred solution, the appropriate amount of an aqueous $\mathrm{NH}_{4} \mathrm{~F}$ (Sigma Aldrich) solution was added producing a $\mathrm{Y}^{3+} / \mathrm{F}^{-}$ratio of $1: 8$. The mixture was poured into a Teflon ${ }^{\mathrm{TM}}$ lined autoclave (Parr Instruments, Moline, Illinois, USA) and subsequently heated at $200{ }^{\circ} \mathrm{C}$ for 4 hours. The obtained nanocrystals was washed several times with ethanol, methanol and finally acetone and dried in an oven at $80{ }^{\circ} \mathrm{C}$.

2.1.3 Other rare earth fluoride nanoparticles. Keeping the procedure similar, different $\mathrm{RE}^{\prime \prime}$ precursors were used, which led to the formation of different phase ternary and binary fluorides. $\mathrm{La}\left(\mathrm{NO}_{3}\right)_{3} \cdot 6 \mathrm{H}_{2} \mathrm{O} ; \mathrm{Ce}\left(\mathrm{NO}_{3}\right)_{3} \cdot 6 \mathrm{H}_{2} \mathrm{O} ; \mathrm{Nd}\left(\mathrm{NO}_{3}\right)_{3} \cdot 5 \mathrm{H}_{2} \mathrm{O}$; $\mathrm{Sm}\left(\mathrm{NO}_{3}\right)_{3} \cdot 5 \mathrm{H}_{2} \mathrm{O} ; \mathrm{Gd}\left(\mathrm{NO}_{3}\right)_{3} \cdot 6 \mathrm{H}_{2} \mathrm{O} ; \mathrm{Tb}\left(\mathrm{NO}_{3}\right)_{3} \cdot 5 \mathrm{H}_{2} \mathrm{O} ; \mathrm{Dy}\left(\mathrm{NO}_{3}\right)_{3}-$ $\cdot 5 \mathrm{H}_{2} \mathrm{O}$ and $\mathrm{Yb}\left(\mathrm{NO}_{3}\right)_{3} \cdot 5 \mathrm{H}_{2} \mathrm{O}$ are purchased from the Alfa Aesar in a purity of $99.9 \%$. Details on the synthesis condition can be found in Table 1.

\subsection{Characterization}

PXRD (powder X-ray diffraction) measurements were carried out on a Huber G70 diffractometer (Rimsting, Germany) using Mo$\mathrm{K} \alpha$ radiation $(\lambda=0.07107 \mathrm{~nm})$. The crystallite size was calculated using the Scherer equation $D=K \lambda / \beta \cos \theta$, where $K=0.9$, $D$ represents crystallite size $(\AA), \lambda$ is the wavelength of the Mo-K $\alpha$ radiation, and $\beta$ is the corrected half-width of the diffraction peak. TEM (transmission electron microscopy; a FEI Tecnai STWIN-T30 using $300 \mathrm{kV}$ electron beam source) was used to investigate the shape, size and lattice structure of the nanocrystals dispersed on a carbon coated copper grid from acetone solution. Morphological characterization was also carried out by SEM (scanning electron microscopy) using a NOVA NANO SEM-450, FEI. Excitation, emission spectra and decay time of all samples were recorded on a Fluorolog 3 (HORIBA JOBIN YVON, Germany) luminescence spectrometer equipped with steady and pulsed Xe lamps for sample excitation and a photomultiplier for signal detection.

\section{Result and discussion}

\subsection{Structural characterization by powder X-ray diffraction and phase evolution}

Solvothermal conversion of sodium chloride and an appropriate amount of yttrium and europium nitrate in ethanol/water solution in the presence of $\left[\mathrm{C}_{2} \mathrm{mim}\right] \mathrm{Br}$ yielded nanosized $\mathrm{NaYF}_{4}: \mathrm{Eu}^{3+}(\mathrm{P} 1)$. For a reaction time of 4 hours at $200{ }^{\circ} \mathrm{C}$, only cubic $\mathrm{NaYF}_{4}: \mathrm{Eu}^{3+}$ (P1) is obtained (Fig. 1a). A detailed study of the effect of the $\mathrm{IL}$, reaction temperature and reactant ratio $\left(\mathrm{Ln}^{3+} / \mathrm{F}^{-}\right)$has already been reported by us earlier. ${ }^{14}$ Now this synthesis protocol is explored for other elements of the rare earth series. It turned out that, depending on the rare earth ion 
Table 1 Summary of the reaction conditions maintained to prepare different binary and ternary fluorides

\begin{tabular}{|c|c|c|c|c|c|c|}
\hline Name of the sample & Crystal phase & $\begin{array}{l}\text { Crystallite } \\
\text { size (nm) }\end{array}$ & $\begin{array}{l}\text { Reaction time } \\
\text { \& temperature }\end{array}$ & $\begin{array}{l}\text { Concentration } \\
\text { of } \mathrm{NaCl} \text { solution/M }\end{array}$ & $\begin{array}{l}\text { Concentration of } \\
\text { the rare-earth } \\
\text { nitrate solution/M }\end{array}$ & $\begin{array}{l}\text { Concentration } \\
\text { of } \mathrm{NH}_{4} \mathrm{~F} \text { solution/M }\end{array}$ \\
\hline $\mathrm{NaYF}_{4}: \mathrm{Eu}^{3+}(\mathrm{P} 1)$ & Cubic & 17.32 & $4 \mathrm{~h} \& 200^{\circ} \mathrm{C}$ & 0.265 & 0.265 & 2.126 \\
\hline $\mathrm{LaF}_{3}: \mathrm{Dy}^{3+}(\mathrm{P} 2)$ & Trigonal & 10.30 & $4 \mathrm{~h} \& 200{ }^{\circ} \mathrm{C}$ & 0.21 & 0.21 & 1.680 \\
\hline $\mathrm{CeF}_{3}(\mathrm{P} 3)$ & Trigonal & 11.8 & $4 \mathrm{~h} \& 200{ }^{\circ} \mathrm{C}$ & 0.21 & 0.21 & 1.680 \\
\hline $\mathrm{CeF}_{3}: \mathrm{Tb}^{3+}(\mathrm{P} 4)$ & Trigonal & 12.03 & $4 \mathrm{~h} \& 200^{\circ} \mathrm{C}$ & 0.208 & 0.209 & 1.671 \\
\hline $\mathrm{NdF}_{3}(\mathrm{P} 5)$ & Trigonal & 14.8 & $4 \mathrm{~h} \& 200^{\circ} \mathrm{C}$ & 0.205 & 0.205 & 1.644 \\
\hline $\mathrm{NaSmF}_{4}(\mathrm{P} 6)$ & Hexagonal & 10.41 & $4 \mathrm{~h} \& 200^{\circ} \mathrm{C}$ & 0.200 & 0.200 & 1.644 \\
\hline $\mathrm{NaGdF}_{4}: \mathrm{Eu}^{3+}(\mathrm{P} 7)$ & Hexagonal & 9.13 & $4 \mathrm{~h} \& 200{ }^{\circ} \mathrm{C}$ & 0.196 & 0.196 & 1.568 \\
\hline $\mathrm{NaTbF}_{4}: \mathrm{Ce}^{3+}(\mathrm{P} 8)$ & Hexagonal & 7.59 & $4 \mathrm{~h} \& 200^{\circ} \mathrm{C}$ & 0.193 & 0.193 & 1.55 \\
\hline $\mathrm{NaDyF}_{4}(\mathrm{P} 9)$ & $\begin{array}{l}\text { Hexagonal (major) + } \\
\text { cubic (minor) }\end{array}$ & 25.8 & $4 \mathrm{~h} \& 200^{\circ} \mathrm{C}$ & 0.188 & 0.190 & 1.526 \\
\hline $\mathrm{NaErF}_{4}: \mathrm{Yb}^{3+}(\mathrm{P} 10)$ & Cubic & 16.56 & $4 \mathrm{~h} \& 200{ }^{\circ} \mathrm{C}$ & 0.187 & 0.187 & 1.502 \\
\hline $\mathrm{NaYbF}_{4}: \mathrm{Er}^{3+}(\mathrm{P} 11)$ & Cubic & 9.5 & $4 \mathrm{~h} \& 200^{\circ} \mathrm{C}$ & 0.184 & 0.184 & 1.47 \\
\hline
\end{tabular}

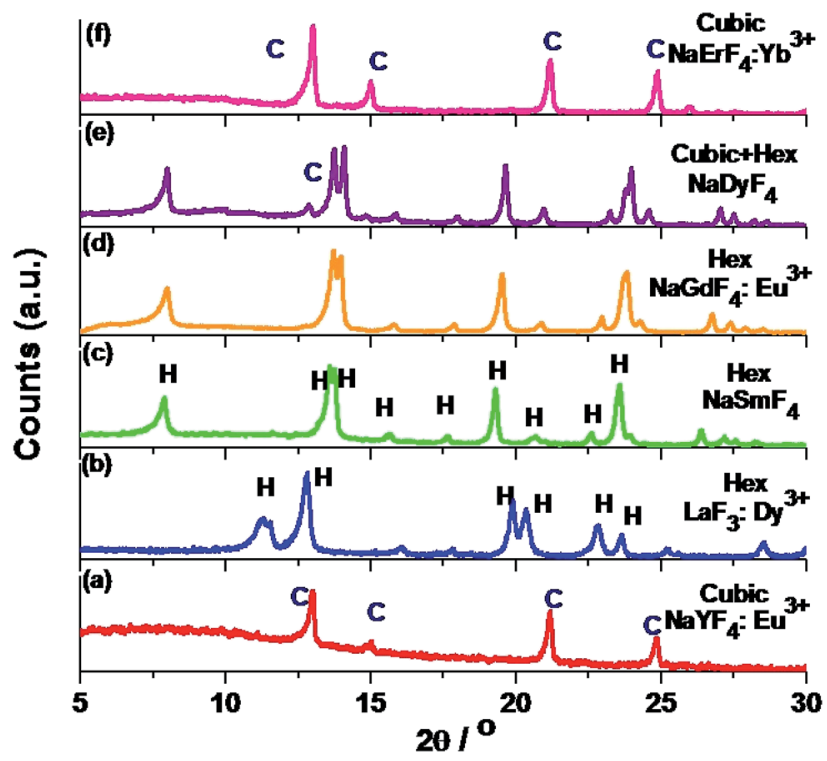

Fig. 1 PXRD pattern of (a) $\mathrm{NaYF}_{4}: \mathrm{Eu}^{3+}$ nanocrystals prepared by the IL assisted solvothermal synthesis at $200{ }^{\circ} \mathrm{C}$ with 4 hours reaction time; $(b-e)$ and (f) PXRD patterns of trigonal $\mathrm{LaF}_{3}: \mathrm{Dy}^{3+}$, hexagonal $\mathrm{NaSmF}_{4}$, $\mathrm{NaGdF}_{4}: \mathrm{Eu}^{3+}$, Hex (major) + cubic (minor) $\mathrm{NaDyF}_{4}$ and pure cubic $\mathrm{NaErF}_{4}: \mathrm{Yb}^{3+}$ prepared with different dopant ions $\left(\mathrm{La}^{3+}, \mathrm{Sm}^{3+}, \mathrm{Gd}^{3+}\right.$, $\mathrm{Dy}^{3+}$ and $\mathrm{Er}^{3+}$ ) under otherwise similar conditions. In all cases, $\mathrm{Ln}^{3+} / \mathrm{F}^{-}$ ratio is taken as $1: 8$.

size, different products, either a ternary $\mathrm{NaREF}_{4}$ polymorph or binary $\mathrm{REF}_{3}$ in the tysonite type of structure are obtained (Fig. 1 and Scheme 1). In the case of $\mathrm{Y}^{3+}$, with an ionic radius of $1.075 \AA$ (using the Shannon radius ${ }^{47}$ for a 9-fold co-ordination) cubic $\mathrm{NaYF}_{4}$ (P1) (Fig. 1) nanocrystals are obtained. For RE ${ }^{3+}$ ions with an ionic radius in the range of 1.13 to $1.095 \AA$ (for $\mathrm{Sm}^{3+}$ to $\mathrm{Tb}^{3+}$ ), hexagonal sodium ternary fluoride $\left(\mathrm{NaLnF}_{4}: \mathrm{Ln}=\mathrm{Sm}^{3+}, \mathrm{Gd}^{3+}\right.$, $\mathrm{Tb}^{3+}$ (P6-P8) in Table 1) is obtained (see Fig. 1, S1† and Table 1).

Interestingly, for $\mathrm{Dy}^{3+}$ where the ionic radius is in between that of $\mathrm{Tb}^{3+}$ and $\mathrm{Er}^{3+}$, the cubic modification starts to appear with the majority phase being hexagonal (P9) (as shown in Fig. 1). When the ionic radius is lesser due to lanthanide contraction as in case of $\mathrm{Er}^{3+}(1.062 \AA)$ and $\mathrm{Yb}^{3+}(1.042 \AA)$ only the cubic polymorph $\left(\mathrm{NaErF}_{4}\right.$ and $\mathrm{NaYbF}_{4}, \mathrm{P} 10$ and P11) is obtained (Fig. 1, S1† and Table 1). At the start of the lanthanide series (for example, for $\mathrm{La}^{3+}$ with an ionic radius of $1.216 \AA$ ), the formation of the binary rare earth fluoride (P2) instead of the ternary fluoride is observed and this trend is maintained until $\mathrm{Nd}^{3+}$ (ionic radius $1.163 \AA$ ). It can be anticipated that for smaller size, as for $\mathrm{Y}^{3+}$ and for $\mathrm{Er}^{3+}, \mathrm{Yb}^{3+}$, the reaction rate is quite faster which leads to the formation of the kinetic product, the cubic phase. When the size of the $\mathrm{RE}^{3+}$ ion is larger, as for $\mathrm{La}^{3+}$, the reaction rate is slower causing the formation of the binary fluoride instead of the ternary fluoride. For $\mathrm{RE}^{3+}$ ions within the range of 1.132 to $1.093 \AA$, reaction rate is optimum for the generation of thermodynamically stable hexagonal ternary fluoride. This kind of phase tuning depending on the size of the $\mathrm{RE}^{3+}$ ion is novel and not previously reported to the best of our knowledge.

\subsection{Lattice strain}

Generally, the broadening of the diffraction peaks in a PXRD pattern depends upon strain and crystallite size. It is previously noticed that change in the interatomic distance induces the perturbation in the lattice parameter of crystalline nanomaterials leading to stress generation at nanoscale particles. And it is well known that higher the size-volume ratio more will be the strain at the nanoscale level. ${ }^{53}$ Herein, the lattice strain in the as-prepared nanoparticles can be attributed to the change in ionic radius of the $\mathrm{RE}^{3+}$ of the host materials. Lattice strain is changing with changing the ionic radius of $\mathrm{RE}^{3+}$ ion in lanthanide series. It means, lattice parameter of host lattice is perturbing in period. It is possible to calculate the lattice strain according to the function derived by Williamson and Hall: ${ }^{51}$

$$
\beta \cos \theta / \lambda=1 / D+\eta \sin \theta / \lambda
$$

where $\beta$ is the full width at half-maximum (fwhm), $\theta$ is the diffraction angle, $\lambda$ is the $\mathrm{X}$-ray wavelength, $D$ is the effective crystallite size, and $\eta$ is the effective strain. When plotting $\beta \cos \theta / \lambda$ against $\sin \theta / \lambda$, the strain is the slope and the 


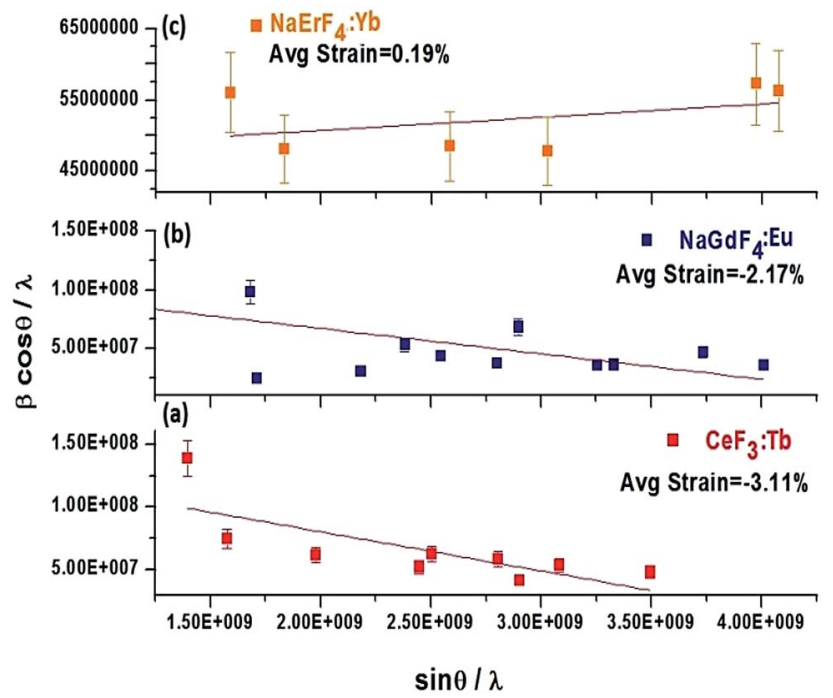

Fig. 2 Plot of $\beta \cos \theta / \lambda$ against $\sin \theta / \lambda$ for $\mathrm{CeF}_{3}: \mathrm{Tb}^{3+}$ (a) $\mathrm{NaGdF}_{4}: \mathrm{Eu}^{3+}$ (b) and $\mathrm{NaErF}_{4}: \mathrm{Yb}^{3+}$ (c) prepared solvothermally using $\left[\mathrm{C}_{2} \mathrm{mim}\right] \mathrm{Br}$ at $200^{\circ} \mathrm{C}$.

crystallite size $(D)$ can be derived from the intercept (Fig. 2 and Table 2). ${ }^{52}$ The lattice strain clearly depends on the size of the rare earth precursor ion. For example, for the binary fluorides where the ionic radius of the precursor RE ion is in the range of $1.216 \AA$ to $1.163 \AA\left(\mathrm{La}^{3+}\right.$ to $\left.\mathrm{Nd}^{3+}\right)$, compressive strain is obtained (Table 2). The lattice strain for $\mathrm{CeF}_{3}: \mathrm{Tb}^{3+}$ (P4) is compressive $(-3.11 \%)$ and the crystallite size obtained from the intercept with the $x$-axis is $17.31 \mathrm{~nm}$ which matches with the size obtained from Scherrer equation (Fig. 2a). Likewise, for the $\mathrm{RE}^{3+}$ ions with medium ionic radius $\left(1.132 \AA\right.$ to $1.083 \AA$ for $\mathrm{Sm}^{3+}$ to $\mathrm{Dy}^{3+}$ ions) where the crystal phase is again hexagonal, the obtained lattice strain is compressive (Table 2). For example for $\mathrm{NaGdF}_{4}(\mathrm{P} 7)$, a compressive strain of $-2.17 \%$ is obtained and crystallite size is $\sim 21 \mathrm{~nm}$ (Fig. 2b). However when the size of the rare earth ion is less, for example, for $\mathrm{Y}^{3+}$ and for $\mathrm{Er}^{3+}$ and $\mathrm{Yb}^{3+}$ due to lanthanide contraction, the cubic phase is observed and a drastic change is noticed in lattice strain i.e., tensile strain is obtained. Fig. 3c shows the plot for $\mathrm{NaErF}_{4}: \mathrm{Yb}^{3+}$ (P10) showing a tensile strain of $+0.19 \%$. Earlier we have reported that cubic sodium yttrium fluoride shows tensile strain however its hexagonal analogue shows compressive strain. Compressive strain is typically observed for smaller crystallite sizes..$^{50}$

\subsection{Structural characterizations by scanning electron microscope}

To investigate the morphology of the nanoparticles, SEM images are analyzed in detail. Fig. 3a shows the SEM images of $\mathrm{CeF}_{3}: \mathrm{Tb}^{3+}$ doped nanocrystals showing nanoparticles with hexagon-like disc shape, whilst for $\mathrm{LaF}_{3}: \mathrm{Dy}^{3+}$ (P2) shows cube like morphology (Fig. S2a $\uparrow$ inset). A clear change in morphology is observed for $\mathrm{NaGdF}_{4}: \mathrm{Eu}^{3+}$ (P7) doped nanocrystals (Fig. 3b). Though the majority of the nanocrystals look spherical, some bunches of cylindrical shape nanostructures are noticed (Fig. 3b). A similar observation is made for $\mathrm{NaDyF}_{4}$ (P9) nanocrystals (Fig. 3c). PXRD analyses show that for both $\mathrm{NaGdF}_{4}$ :$\mathrm{Eu}^{3+}$ and $\mathrm{NaDyF}_{4}$ the hexagonal modification is the majority phase and the cubic the minority. For $\mathrm{NaYF}_{4}$ nanocrystals doped with $\mathrm{Eu}^{3+}$ ions, spherical nanoparticles are obtained (Fig. 3d). Though the crystal phase is same as that of $\mathrm{NaYF}_{4}$ and ionic radius of $\mathrm{Eu}^{3+}$ is comparable with $\mathrm{Y}^{3+}, \mathrm{NaErF}_{4}: \mathrm{Yb}^{3+}(\mathrm{P} 10)$ shows almost monodisperse, oval shaped particles with a higher crystallinity and higher particle size $(16.56 \mathrm{~nm})$ which nicely matches with the crystallite size obtained from the Scherrer equation (Fig. 3e). Interestingly, some cubes can be noticed among the oval shaped nanoparticles (Fig. 3e). A similar observation can be made for the $\mathrm{NaYbF}_{4}: \mathrm{Er}^{3+}$ (P11) nanoparticles (Fig. 3f) though particle size is little bigger.

\subsection{Structural characterizations by transmission electron microscope}

To understand the morphology evolution from its atomistic origin, TEM images are analyzed in detail. 10 representative examples, $\mathrm{LaF}_{3}: \mathrm{Dy}^{3+}$ (P2); $\mathrm{CeF}_{3}: \mathrm{Tb}^{3+}(\mathrm{P} 4) ; \mathrm{NdF}_{3}$ (P5); $\mathrm{NaSmF}_{4}$ (P6); $\mathrm{NaGdF}_{4}: \mathrm{Eu}^{3+}$ (P7); $\mathrm{NaTbF}_{4}: \mathrm{Ce}^{3+}$ (P8); $\mathrm{NaDyF}_{4}$ (P9); $\mathrm{NaYF}_{4}: \mathrm{Eu}^{3+}(\mathrm{P} 1) ; \mathrm{NaErF}_{4}: \mathrm{Yb}^{3+}(\mathrm{P} 10)$ and $\mathrm{NaYbF}_{4}: \mathrm{Er}^{3+}(\mathrm{P} 11)$ are taken from the three classes of fluoride materials made based on the ionic radius/size of the $\mathrm{RE}^{3+}$ ion.

From Fig. $4 \mathrm{a}$ and $\mathrm{b}$, it is noticed that hexagonal benzene like particles were found which have narrow range of aspect ratio

Table 2 Lattice strain of binary and ternary rare-earth fluoride nanomaterials prepared by a solvothermal method using $\left[\mathrm{C}_{2} \mathrm{mim}\right] \mathrm{Br} I \mathrm{~L}$ at $200{ }^{\circ} \mathrm{C}$

\begin{tabular}{|c|c|c|c|c|c|c|}
\hline S. no. & Sample & Ionic radius $(\AA)$ & Crystal phase & Average strain $( \pm 5.0 \%)$ & Crystallite size $(\mathrm{nm})^{a}$ & Lattice strain \\
\hline 1. & $\mathrm{LaF}_{3}: \mathrm{Dy}^{3+}(\mathrm{P} 2)$ & 1.216 & Trigonal & -8.1 & $11.83( \pm 0.2)$ & Compressive \\
\hline 2. & $\mathrm{CeF}_{3}: \mathrm{Tb}^{3+}(\mathrm{P} 4)$ & 1.196 & Trigonal & -3.11 & $17.31( \pm 0.2)$ & Compressive \\
\hline 4. & $\mathrm{NaSmF}_{4}(\mathrm{P} 6)$ & 1.132 & Hexagonal & -1.245 & $19.68( \pm 0.2)$ & Compressive \\
\hline 5. & $\mathrm{NaGdF}_{4}: \mathrm{Eu}^{3+}(\mathrm{P} 7)$ & 1.107 & Hexagonal & -2.17 & $20.99( \pm 0.2)$ & Compressive \\
\hline 6. & $\mathrm{NaTbF}_{4}(\mathrm{P} 8)$ & 1.095 & Hexagonal & -1.87 & $23.09( \pm 0.2)$ & Compressive \\
\hline 9. & $\mathrm{NaErF}_{4}: \mathrm{Yb}^{3+}(\mathrm{P} 10)$ & 1.062 & Cubic & +0.19 & $15.99( \pm 0.3)$ & Tensile \\
\hline 10. & $\mathrm{NaYbF}_{4}: \mathrm{Er}^{3+}(\mathrm{P} 11)$ & 1.042 & Cubic & +0.7 & $22.5( \pm 0.2)$ & Tensile \\
\hline
\end{tabular}

${ }^{a}$ Estimated deviation. 

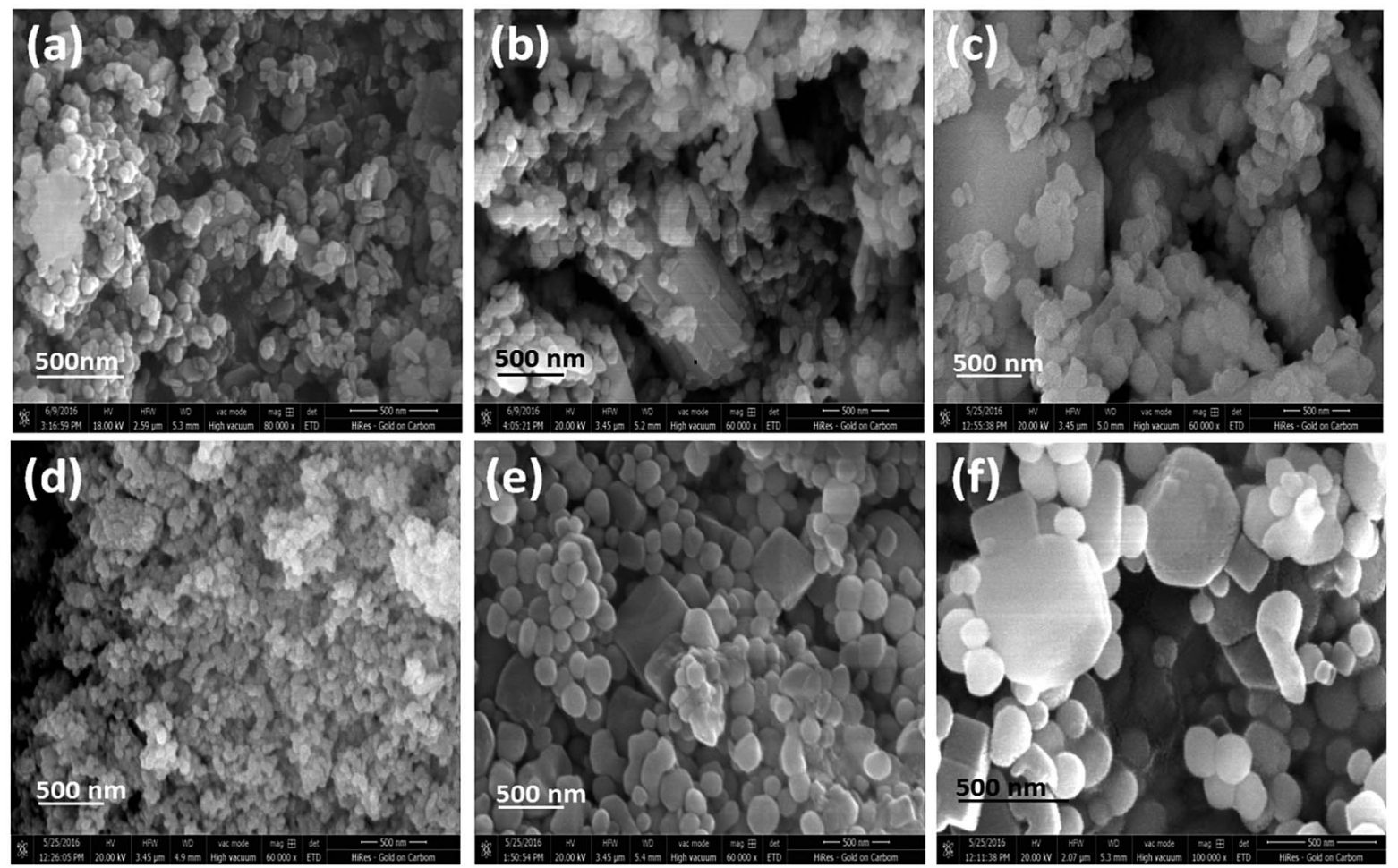

Fig. 3 Scanning electron microscope (SEM) images of (a) $\mathrm{CeF}_{3}: \mathrm{Tb}^{3+}$ (b) $\mathrm{NaGdF}_{4}: \mathrm{Eu}^{3+}$ (c) $\mathrm{NaDyF}_{4}$ (d) $\mathrm{NaYF}_{4}: \mathrm{Eu}^{3+}$ (e) $\mathrm{NaErF}_{4}: \mathrm{Yb}^{3+}$ and (f) $\mathrm{NaYbF}_{4}: \mathrm{Er}^{3+}$ nanoparticles prepared solvothermally in the presence of $\left[\mathrm{C}_{2} \mathrm{mim}\right] \mathrm{Br}$ at $200{ }^{\circ} \mathrm{C}$

(ca. 1.15 to 2.4). Most of the particles are isotropic (length of diagonal is same) in size. Small size particles are usually spherical whereas well matured particles have attended the highly regular hexagonal like shape. From HRTEM images, it can be seen that the growth of these particles are predominantly occurring along the (111) plane (as shown in Fig. $5 a$ and b). And the spacing between the planes is $0.325 \mathrm{~nm}$ for the $\mathrm{CeF}_{3}$. So it can be inferred that the $\left[\mathrm{C}_{2} \mathrm{mim}\right]^{+}$ion can serve as a capping agent based on the strong interaction with the (111) facets which favour the directional growth of the hexagonal phase. As the most exposed facets of the $\mathrm{CeF}_{3}: \mathrm{Tb}^{3+}$ nanorods are (111) planes, the energy difference between them is minimal, facilitating the oriented attachment via twin boundaries which is noticed in the encircled area of Fig. $5 b^{.54,55}$

The shape of the particles was also confirmed through the SAED images of $\mathrm{LaF}_{3}$ and $\mathrm{CeF}_{3}$, where single crystalline hexagonal diffraction patterns were observed (Fig. S5a and b广). Bright diffracting planes are belonging to (111), (112), (113), (300), (311) and (111), (112), (113), (222) planes of the $\mathrm{LaF}_{3}$ and $\mathrm{CeF}_{3}$ respectively. Thus, it is evidently confirmed that (111) plane is the dominating plane for both $\mathrm{LaF}_{3}$ and $\mathrm{CeF}_{3}$ nanoparticles (shown in Fig. S5a and $b_{\dagger} \dagger$ ). Furthermore, $a^{\prime} b^{\prime}$ and $b^{\prime} c^{\prime}$ planes are equally spaced $\left(3.16 \mathrm{~nm}^{-1}\right)$ and edge length of the drawn benzene like shape is $5.51 \mathrm{~nm}^{-1}$ in $\mathrm{CeF}_{3}: \mathrm{Tb}^{3+}$ single crystal (see Fig. S5b $\mathrm{b}^{\dagger}$ ). However, in the case of $\mathrm{NdF}_{3}$ significant changes in the shape were noticed (Fig. 4c). Here mixed (hexagonal, spherical and few tubular) morphology is found with wide range of particle size. Aspect ratio (1.020-8.55) of these particles is abruptly increased than the $\mathrm{LaF}_{3}$ and $\mathrm{CeF}_{3}$ nanoparticles.
Analysis reveals that regularity of hexagonal structure is gradually decreased from La to $\mathrm{Nd}$. This is attributed to the contraction of crystal lattice volume of binary rare earth fluorides with decreasing the ionic radius of $\mathrm{RE}^{3+}$ ions. Consequently, anisotropic growth of the nanoparticle would be occurred in distorted hexagonal/trigonal unit cell. Therefore regularity of hexagonal disc is gradually being transformed to distorted hexagonal form.

However, in ternary hexagonal $\mathrm{NaREF}_{4}$ (Sm to $\mathrm{Tb}$ ), shape of the particles is drastically changed into irregular, branchedtubular shape with higher aspect ratio $(c a .1 .14-9.8)$ that is much higher than the previous binary fluorides i.e. $\mathrm{NdF}_{3}$ (as shown in Fig. $4 \mathrm{c}$ and d). As can be seen from the TEM images, dispersibility of these particles is gradually decreasing from $\mathrm{NaSmF}_{4}$ to $\mathrm{NaTbF}_{4}: \mathrm{Ce}^{3+}$. In the case of $\mathrm{NaSmF}_{4}$ obtained nanoparticles are highly dispersed whereas in the case of $\mathrm{NaTbF}_{4}$ particles are agglomerated. Here, (101) plane is highly exposed plane with spacing of $0.298 \mathrm{~nm}$ for the hexagonal $\mathrm{NaGdF}_{4}: \mathrm{Eu}^{3+}$ nanoparticles (see Fig. 5c). From low magnification TEM images, it can be prominently seen that the however, in HRTEM image of the $\mathrm{NaDyF}_{4}$, both (111) [cubic] and (101) [hexagonal] planes are appearing (Fig. 5d). The calculated spacing $(0.315 \mathrm{~nm})$ between the lattice fringes is belonging to the (111) plane of the cubic $\mathrm{NaDyF}_{4}$ nanoparticles. SAED image of the same sample indicates that it is polycrystalline in nature and diffracting planes correspond to the (112), (300) and (311) planes (see in Fig. S5c and d $\dagger$ ). In present cases, distribution of sodium and $\mathrm{RE}^{3+}$ is completely different than that of binary rare earth fluorides. Hexagonal unit cell of ternary rare-earth 

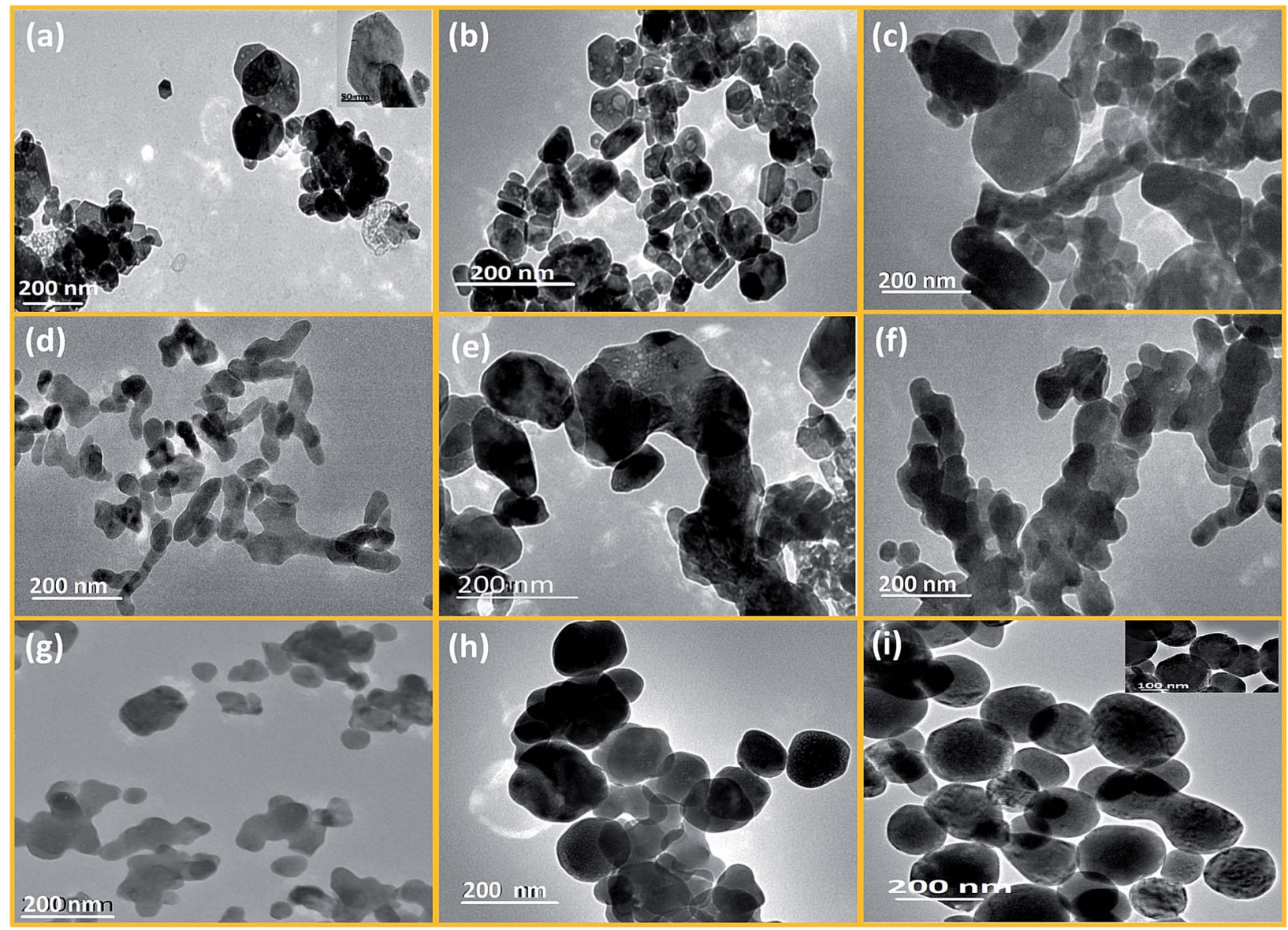

Fig. 4 Low magnification TEM images of $\mathrm{LaF}_{3}: \mathrm{Dy}^{3+}, \mathrm{CeF}_{3}: \mathrm{Tb}^{3+}, \mathrm{NdF}_{3}$ (a-c) $\mathrm{NaSmF}_{4}, \mathrm{NaGdF}_{4}: \mathrm{Eu}^{3+}, \mathrm{NaTbF}_{4}: \mathrm{Ce}^{3+}$ (d-f) and $\mathrm{NaYF}_{4}: \mathrm{Eu}^{3+}$, $\mathrm{NaErF}_{4}: \mathrm{Yb}^{3+}, \mathrm{NaYbF}_{4}: \mathrm{Er}^{3+}(\mathrm{g}-\mathrm{i})$ nanocrystals prepared solvothermally at $200{ }^{\circ} \mathrm{C}$.

fluorides are contracting gradually due to contraction of interatomic bond length and causes anisotropic growth leading to the formation of tubular structure. Furthermore, on moving from $\mathrm{Sm}$ to $\mathrm{Tb}$, dispersibility of tubular nanoparticles is also decreasing (as shown in Fig. $4 \mathrm{~d}-\mathrm{f}$ ), which is attributed to the increased surface energy. In period, charge density $(e / r)$ gradually increases with decreasing the ionic radius of $\mathrm{RE}^{3+}$. Consequently, surface energy increases and agglomeration of particles is taken place. On the other hand, mixed phase is obtained in $\mathrm{NaDyF}_{4}$. Since cubic phase is appearing along with hexagonal phase so irregular spherical as well as tubular both types morphology are obtained (Fig. S3 $\uparrow$ ). In other words, it can be said that $\mathrm{Dy}^{3+}$ is the conduit ion between hexagonal and cubic phase of ternary rare earth fluorides.

In the case of small size $\mathrm{RE}^{3+}$ ions (1.075-1.042 $⿱$ )), nicely dispersed, relatively more spherical-shaped nanoparticles are obtained (Fig. 4g-i). This group of $\mathrm{RE}^{3+}$ ions forms cubic ternary rare-earth fluoride nanoparticles under the similar experimental conditions. Significant changes are noticed in the shape of the cubic phase $\mathrm{NaYF}_{4}$ to $\mathrm{NaYbF}_{4}$ nanoparticles. Aspect ratio of these particles is gradually decreasing to the unity and the shape is getting increasingly spherical. It was further confirmed from the HRTEM images, that in $\mathrm{NaErF}_{4}: \mathrm{Yb}^{3+}$ major planes are (111) and (200), while (111) is the only dominating plane in case of $\mathrm{NaYbF}_{4}: \mathrm{Er}^{3+}$ (see Fig. 5e and f). Besides this, dispersity of the nanoparticles is also increasing along with shape from $\mathrm{NaYF}_{4}$ to $\mathrm{NaYbF}_{4}$. From the diffraction patterns, it is evident that asprepared nanoparticles are polycrystalline and planes can be assigned to (222), (422), (400) and (311), (222), (331) for $\mathrm{NaErF}_{4}: \mathrm{Yb}^{3+}$ and $\mathrm{NaYbF}_{4}: \mathrm{Er}^{3+}$ nanoparticles respectively (Fig. S5e and $\mathrm{f}_{\dagger} \dagger$ ).

In cubic phase all lattice parameters $(a=b=c)$ of the unit cell are same. So the growth of the as-prepared nanoparticles would be isotropic. Promptness of spherical shape is dependent on the isotropic nature of cubic phase. For example, relatively large ion is forming irregular spherical nanoparticles (for example $\mathrm{NaYF}_{4}$ ) while more spherical nanoparticles are found in $\mathrm{NaErF}_{4}: \mathrm{Yb}$ and $\mathrm{NaYbF}_{4}: \mathrm{Er}$. And the average size of nanoparticles are $c a .55 .3 \mathrm{~nm}, 104.95 \mathrm{~nm}$ and $151.63 \mathrm{~nm}$ for $\mathrm{NaYF}_{4}: \mathrm{Eu}, \mathrm{NaErF}_{4}: \mathrm{Yb}$ and $\mathrm{NaYbF}_{4}: \mathrm{Er}$ respectively. From Fig. $S 4, \uparrow$ in histogram it can be nicely seen that size distribution of the particles are very much comparable to the calculated average size of the nanoparticles. Moreover, narrow range of size distribution is observed for the $\mathrm{NaYF}_{4}: \mathrm{Eu}$ nanoparticles whereas wide range of size distribution is occurred in case of $\mathrm{NaYbF}_{4}$ :Er (Fig. S4†). Thus from TEM images it can be said that isotropic nature of cubic phase is increasing with decreasing the ionic radius of $\mathrm{RE}^{3+}$ ions in period. Thus from all observations it 

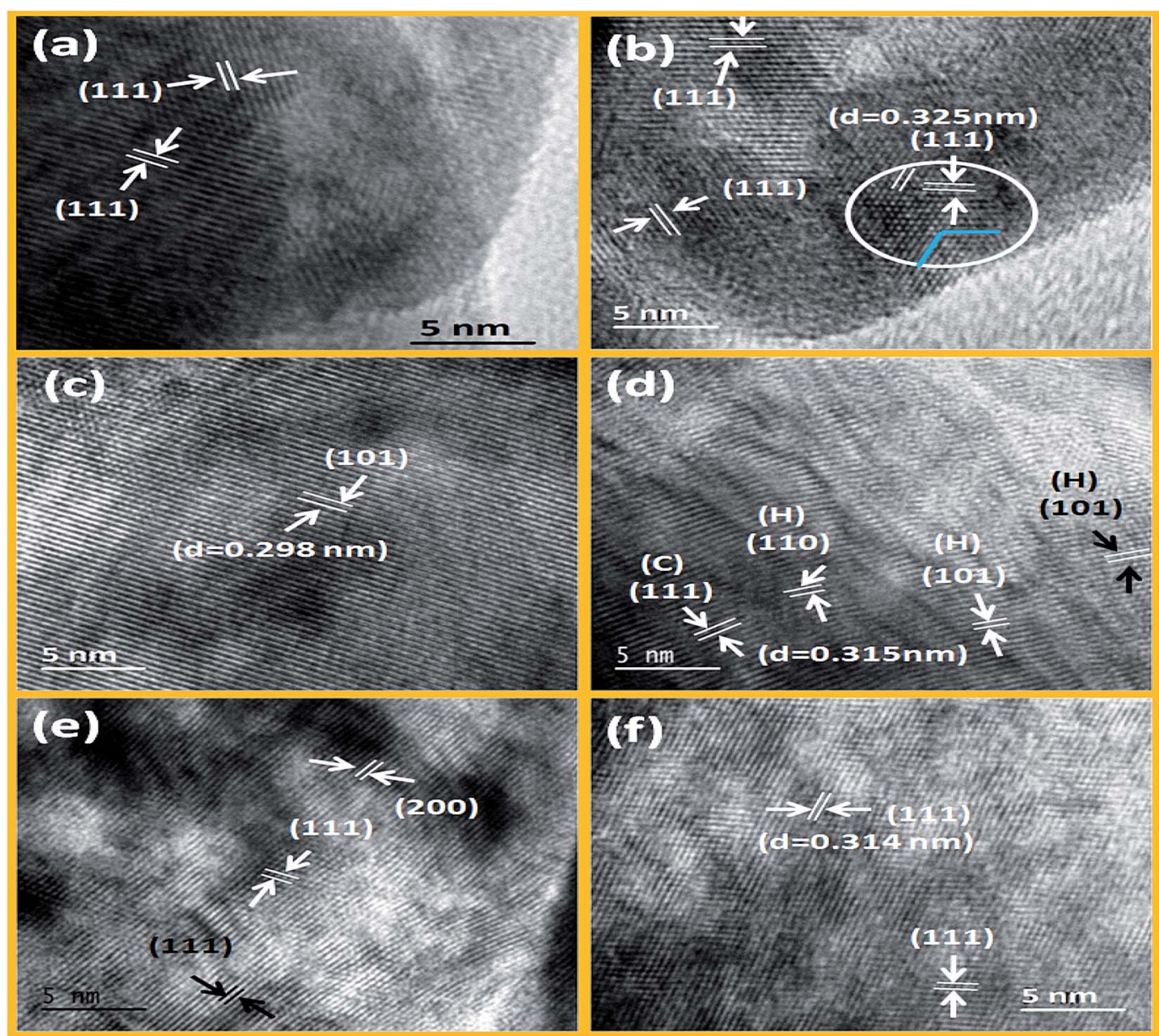

Fig. 5 HRTEM images of $\mathrm{LaF}_{3}: \mathrm{Dy}^{3+}, \mathrm{CeF}_{3}: \mathrm{Tb}^{3+}$ (a and b) $\mathrm{NaGdF}_{4}: \mathrm{Eu}^{3+}, \mathrm{NaDyF}_{4}$ (c and d) and $\mathrm{NaErF}_{4}: \mathrm{Yb}^{3+}, \mathrm{NaYbF}_{4}: \mathrm{Er}^{3+}$ (e and f) nanocrystals prepared solvothermally at $200^{\circ} \mathrm{C}$.

can be inferred that $\mathrm{RE}^{3+}$ ions in period not only governs the phase and type of products but also controlled morphology of the as-obtained products under similar reaction conditions (Fig. 6).

\subsection{Optical characterizations}

Fig. 7 and S7 $\dagger$ depicts the photoluminescence (PL) spectra of eight representative compounds, cubic $\mathrm{NaYF}_{4}: \mathrm{Eu}^{3+}$ (P1), hexagonal $\mathrm{NaGdF}_{4}: \mathrm{Eu}^{3+}(\mathrm{P} 7)$, hexagonal $\mathrm{CeF}_{3}(\mathrm{P} 3), \mathrm{CeF}_{3}: \mathrm{Tb}^{3+}$ (P4), $\mathrm{LaF}_{3}: \mathrm{Dy}^{3+}(\mathrm{P} 2), \mathrm{NaSmF}_{4}(\mathrm{P} 6), \mathrm{NaTbF}_{4}$ :Ce (P8) and $\mathrm{NaDyF}_{4}$ (P9) respectively. Fig. 7a shows the excitation spectra of $1 \mathrm{~mol} \%$ $\mathrm{Eu}^{3+}$ doped $\mathrm{NaGdF}_{4}$ nanocrystals measured at room temperature, monitoring the ${ }^{5} \mathrm{D}_{0}-{ }^{7} \mathrm{~F}_{2}$ electric dipole transition of the $\mathrm{Eu}^{3+}$ ion at $615 \mathrm{~nm}$. Narrow transition lines of $\mathrm{Gd}^{3+}$ at $272 \mathrm{~nm}$ $\left({ }^{8} \mathrm{~S}_{7 / 2}{ }^{6} \mathrm{I}_{J}\right)$ and $310 \mathrm{~nm}\left({ }^{8} \mathrm{~S}_{7 / 2}-{ }^{6} \mathrm{P}_{J}\right)$ along the characteristic ones of $\mathrm{Eu}^{3+}$ especially at $393 \mathrm{~nm}$ appear. Fig. $7 \mathrm{~b}$ shows the PL spectrum of hexagonal $\mathrm{NaGdF}_{4}: \mathrm{Eu}^{3+}$ nanocrystals obtained upon $393 \mathrm{~nm}$

\section{Evolution of Morphology}

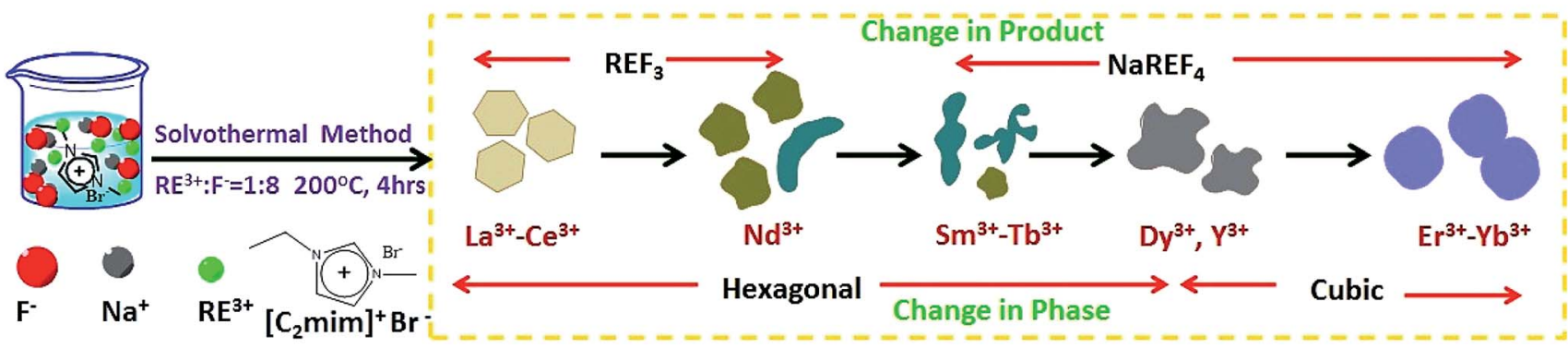

Fig. 6 Schematic presentation of trend of morphology evolution of binary/ternary rare-earth fluorides along the period of lanthanide series. 


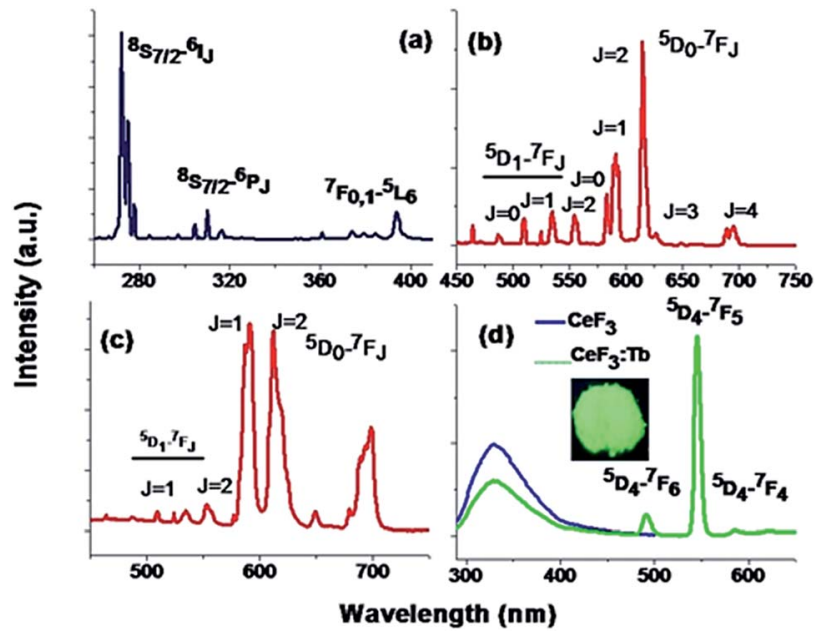

Fig. 7 (a) Excitation spectrum of $\mathrm{NaGdF}_{4}: \mathrm{Eu}^{3+}$ nanocrystals $\left(\lambda_{\text {em }}=615\right.$ $\mathrm{nm}$ ); (b) emission spectra of $\mathrm{NaGdF}_{4}: \mathrm{Eu}^{3+}$; and (c) $\mathrm{NaYF}_{4}: \mathrm{Eu}^{3+}$ nanocrystals measured upon excitation at $393 \mathrm{~nm}$ (d) $\mathrm{CeF}_{3}$; as well as $\mathrm{CeF}_{3}: \mathrm{Tb}^{3+}$ nanocrystals measured upon excitation at $270 \mathrm{~nm}$.

excitation. It shows the electric dipole transition arises due to ${ }^{5} \mathrm{D}_{0}-{ }^{7} \mathrm{~F}_{2}$ at $615 \mathrm{~nm}$ which is stronger than the magnetic dipole transitions arise at $591 \mathrm{~nm}$. The asymmetry parameter $\left(\Omega_{2}\right)$ using Judd-Ofelt theory was calculated for better understanding [for details see ESI $\dagger]^{56,57}$ Calculated $\Omega_{2}$ value for the above mentioned sample is $11.6 \times 10^{-20} \mathrm{~cm}^{2}$. When $\mathrm{Eu}^{3+}$ ions doped in cubic $\mathrm{NaYF}_{4}$ under excitation at $393 \mathrm{~nm}$, the magnetic dipole transition shows stronger emission than the electric dipole transition. This indicates that $\mathrm{Eu}^{3+}$ ion is staying in more symmetric environment compared to the hexagonal $\mathrm{NaGdF}_{4}$ :$\mathrm{Eu}^{3+}$ sample. This is further confirmed by the lower asymmetry parameter $\Omega_{2}$ value of $3.75 \times 10^{-20} \mathrm{~cm}^{2}$ for cubic $\mathrm{Eu}^{3+}$ ion doped $\mathrm{NaYF}_{4}$ nanoparticles. Thus the $\mathrm{Eu}^{3+}$ ion can be used as a spectroscopic probe to monitor phase transition. Another important point which is observed is the presence of the transitions from higher energy levels like ${ }^{5} \mathrm{D}_{1},{ }^{5} \mathrm{D}_{2},{ }^{5} \mathrm{D}_{3}$ etc. in both the cubic $\mathrm{NaYF}_{4}$ and hexagonal $\mathrm{NaGdF}_{4}$ doped with $\mathrm{Eu}^{3+}$. This hints that these materials can be useful for quantum cutting down conversion purposes which has potential use in energy saving lighting devoid of mercury. ${ }^{\mathbf{1 4 , 5 0}}$ Fig. S7a $\uparrow$ shows the emission spectrum of $\mathrm{LaF}_{3}: \mathrm{Dy}^{3+}(1 \%)$ under $348 \mathrm{~nm}$ excitation. The emission peaks appear at $475 \mathrm{~nm}$ and $571 \mathrm{~nm}$ and are assigned to ${ }^{4} \mathrm{~F}_{9 / 2}-{ }^{6} \mathrm{H}_{15 / 2}$ and ${ }^{4} \mathrm{~F}_{9 / 2}-{ }^{6} \mathrm{H}_{13 / 2}$ transitions respectively. When $\mathrm{NaDyF}_{4}$ nanoparticles are excited under $348 \mathrm{~nm}$ excitation, emission peak at $469 \mathrm{~nm}$ appears which is due to ${ }^{4} \mathrm{~F}_{9 /}$ ${ }_{2}-{ }^{6} \mathrm{H}_{15 / 2}$ transition (Fig. S7 $\mathrm{d} \dagger$ ). In the case of $\mathrm{NaSmF}_{4}$, very weak emission at $600 \mathrm{~nm}$ is found on exciting the nanoparticles under $365 \mathrm{~nm}$. This transition corresponds to ${ }^{4} \mathrm{G}_{5 / 2}-{ }^{6} \mathrm{H}_{7 / 2}$ of $\mathrm{NaSmF}_{4}$ (as shown in Fig. $\mathrm{S} 7 \mathrm{~b} \dagger$ ).

Fig. 7d shows the emission spectra of $\mathrm{CeF}_{3}$ and $\mathrm{CeF}_{3}: \mathrm{Tb}^{3+}$ nanocrystals dispersed in dimethyl sulphoxide (DMSO) solution and excited into the $4 \mathrm{f}-5 \mathrm{~d}$ absorption band of $\mathrm{Ce}^{3+}$. A broad emission band ranging from $300 \mathrm{~nm}$ to $400 \mathrm{~nm}$ with a maximum of $330 \mathrm{~nm}$ is observed for $\mathrm{CeF}_{3}$. Parity allowed transition of the lowest component of the ${ }^{2} \mathrm{D}$ state to the spinorbit components of the ground state ${ }^{2} \mathrm{~F}_{5 / 2,7 / 2}$ of $\mathrm{Ce}^{3+}$ ion is the cause of the origin of this particular emission band. A strong excitation peak near $270 \mathrm{~nm}$ monitored with the emission wavelength of $330 \mathrm{~nm}$ corresponds to the transitions from the ground state ${ }^{2} \mathrm{~F}_{5 / 2}$ of $\mathrm{Ce}^{3+}$ to the different components of the excited $\mathrm{Ce}^{3+} 5 \mathrm{~d}$ states (Fig. S6 $\dagger$ ). ${ }^{58}$ During the excitation of $\mathrm{CeF}_{3}: \mathrm{Tb}^{3+}$ sample (Fig. 7d) a significant decrease in PL intensities of $\mathrm{Ce}^{3+}$ ion occurs and the appearance of new peaks at 490 , 545 and 586 happens. Appearance of these new peaks is due to the transitions of ${ }^{5} \mathrm{D}_{4}{ }^{-}{ }^{7} \mathrm{~F}_{6,5,4}$ for $\mathrm{Tb}^{3+}$ ion. Here, $\mathrm{Ce}^{3+}$ ions are excited first and then energy transfer took place from $\mathrm{Ce}^{3+}$ to $\mathrm{Tb}^{3+}$ ions which non-radiatively decay to the ${ }^{5} \mathrm{D}_{4}$ excited level of $\mathrm{Tb}^{3+}$ ions. Finally radiative decay happens from this level to the various underlying levels of ${ }^{5} \mathrm{~F}_{J=0-6}$ of $\mathrm{Tb}^{3+}$ ions. Incidentally the energy levels of $\mathrm{Tb}^{3+}$ ions are suitable for an energy transfer taking place from the $\mathrm{Ce}^{3+}$ ion upon excitation with an UV source. When $\mathrm{CeF}_{3}: \mathrm{Tb}^{3+}$ powder samples are irradiated with UV light, an intense green colour emission which is due to the magnetic dipole transition $\left({ }^{5} \mathrm{D}_{4}{ }^{-}{ }^{7} \mathrm{~F}_{5}\right)$ with $\Delta J= \pm 1$ of at $545 \mathrm{~nm}$ which can be observed with the bare eye (inset of Fig. 7d). The energy transfer efficiency $\left(\eta_{\mathrm{ET}}\right)$ from donor $\left(\mathrm{Ce}^{3+}\right)$ to acceptor $\left(\mathrm{Tb}^{3+}\right)$ is calculated using the equation $\eta_{\mathrm{ET}}=1-I_{\mathrm{d}} / I_{\mathrm{d} 0}$, where $I_{\mathrm{d} 0}$ and $I_{\mathrm{d}}$ are the luminescence emission intensities of donor in the absence and presence of acceptor $\left(\mathrm{Tb}^{3+}\right)$ respectively. $40.80 \%$ energy transfer efficiency $\left(\eta_{\mathrm{ET}}\right)$ is obtained in DMSO solution. However similar kind of energy transfer from $\mathrm{Ce}^{3+}$ to $\mathrm{Tb}^{3+}$ occurs in case of $\mathrm{NaTbF}_{4}: \mathrm{Ce}^{3+}(\mathrm{P} 8)$ nanocrystal and presented in Fig. S7c. $\dagger$

\section{Conclusions}

In summary, we have succeeded in preparing phase and morphology controlled $\mathrm{RE}^{3+}$ doped binary $\left(\mathrm{LnF}_{3}\right)$ and ternary rare-earth fluoride $\left(\mathrm{NaREF}_{4}\right)$ using an IL-based solvothermal method. Crystal phase, lattice strain, morphology and most importantly nature of fluorides (binary/ternary) are tuned by judiciously selecting the size of the $\mathrm{RE}^{3+}$ ion, keeping the other reaction parameters same. To the best of our knowledge, the phase and morphology tuning on the basis of ionic radius/size of the chosen $\mathrm{RE}^{3+}$ ion are not reported yet. When size of the $\mathrm{RE}^{3+}$ ions are small like for $\mathrm{Y}^{3+}$ ions or for $\mathrm{Er}^{3+}$ and $\mathrm{Yb}^{3+}$, the reaction rate is quite faster and kinetically controlled cubic polymorph of $\mathrm{NaREF}_{4}\left(\mathrm{RE}=\mathrm{Y}^{3+}, \mathrm{Er}^{3+}\right.$ and $\left.\mathrm{Yb}^{3+}\right)$ with spherical morphology is obtained. A drastic change in morphology as well as crystal phase is noticed for $\mathrm{NaREF}_{4}$ with $\mathrm{RE}=\mathrm{Sm}^{3+}, \mathrm{Eu}^{3+}$, $\mathrm{Tb}^{3+}, \mathrm{Gd}^{3+}$. Here the sizes of the $\mathrm{RE}^{3+}$ ions are in intermediate size and the formation of the thermodynamically stable hexagonal phase occurs. When the same reaction technique is attempted for $\mathrm{La}^{3+}, \mathrm{Ce}^{3+}$ and $\mathrm{Nd}^{3+}$, instead of the ternary fluoride, hexagon-shaped particles of the binary fluoride are obtained. This is due to the quite larger size of the $\mathrm{RE}^{3+}$ ion which plays a pivotal role in kinetics. HRTEM analysis shows that the $\left[\mathrm{C}_{2} \mathrm{mim}\right]^{+}$cation attaches to the (111) plane and favor the directional growth of the hexagonal phase $\mathrm{LnF}_{3}$. Analysis reveals that lattice strain can be crystal phase dependent. Both the trigonal binary and hexagonal ternary fluoride shows compressive strain whereas cubic ternary fluoride shows tensile strain. Strong emission peaks, higher energy transition of $\mathrm{Eu}^{3+}$ 
ion for $\mathrm{NaYF}_{4}: \mathrm{Eu}^{3+}$ and $\mathrm{NaGdF}_{4}: \mathrm{Eu}^{3+}$ ion and efficient energy transfer from $\mathrm{Ce}^{3+}$ to $\mathrm{Tb}^{3+}$ shows promises in different optoelectronic applications of prepared lanthanide doped materials. Last but not the least, this methodology based on the ionic radius or size of the ions can be applied for any other series of fluorides in the periodic table.

\section{Acknowledgements}

RKS, YNC and PG would like to acknowledge support from the Science and Engineering Research Board (Start-Up Research Grant for Young Scientist) and UGC Start Up Grant for financial support. RKS acknowledge Dr H. S. Gour University for financial support through a graduate fellowship. AVM acknowledges support from DOE as this work was in part be supported by the Critical Materials Institute. Authors acknowledge the support from Sophisticated Instrumentation Centre (SIC) of Dr H. S. Gour University for SEM and TEM measurements.

\section{Notes and references}

1 F. Wang and X. Liu, Chem. Soc. Rev., 2009, 38, 976.

2 J.-C. Bünzli, Chem. Rev., 2010, 110, 2729.

3 C. Bouzigues, T. Gacoin and A. Alexandrou, ACS Nano, 2011, 11, 8488.

4 G. Chen, T. Y. Ohulchanskyy, S. Liu, W.-C. Law, F. Wu, M. Swihart, H. Ågren and P. N. Prasad, ACS Nano, 2012, 6, 2969.

5 D. A. Chengelis, A. M. Yingling, P. D. Badger, C. M. Shade and S. Petoud, J. Am. Chem. Soc., 2005, 127, 16752.

6 E. C. Ximendes, W. Q. Santos, U. Rocha, U. K. Kagola, F. S-Rodríguez, N. Fernández, A. da S. G-Neto, D. Bravo, A. M. Domingo, B. del Rosal, C. D. S. Brites, L. D. Carlos, D. Jaque and C. Jacinto, Nano Lett., 2016, 16, 1695.

7 J. M. Meruga, A. Baride, W. Cross, J. J. Kellar and P. Stanley May, J. Mater. Chem. C, 2014, 2, 2221.

8 M. Pedroni, F. Piccinelli, T. Passuello, M. Giarola, G. Mariotto, S. Polizzi, M. Bettinelli and A. Speghini, Nanoscale, 2011, 3, 1456.

9 Z. Zhang, X. Ma, Z. Geng, K. Wang and Z. Wang, RSC Adv., 2015, 5, 33999.

10 S. Kasturi, V. Sivakumar and D. Y. Jeon, Luminescence, 2016, 31, 1138.

11 N. Mauser, D. Piatkowski, T. Mancabelli, M. Nyk, S. Mackowski and A. Hartschuh, ACS Nano, 2015, 9, 3617.

12 C. Wang, L. Cheng, Y. Liu, X. Wang, X. Ma, Z. Deng, Y. Li and Z. Liu, Adv. Funct. Mater., 2013, 23, 3077.

13 K. Krämer, D. Biner, G. Frei, H. U. Güdel, M. P. Hehlen and S. R. Lüthi, Chem. Mater., 2004, 16, 1244.

14 P. Ghosh, S. Tang and A.-V. Mudring, J. Mater. Chem., 2011, 21, 8640.

15 P. Rahman and M. Green, Nanoscale, 2009, 1, 214.

16 S. Zeng, G. Ren, C. Xu and Q. Yang, CrystEngComm, 2011, 13, 4276.

17 D. Yang, Y. Dai, P. Ma, X. Kang, M. Shang, Z. Cheng, C. Li and J. Lin, J. Mater. Chem., 2012, 22, 20618.
18 K. A. Abel, J.-C. Boyer and F. C. J. M. van Veggel, J. Am. Chem. Soc., 2009, 131, 14644.

19 H. Wang and T. Nann, ACS Nano, 2009, 3, 3804.

20 J.-C. Boyer, F. Vetrone, L. A. Cuccia and J. A. Capobianco, J. Am. Chem. Soc., 2006, 128, 7444.

21 F. Wang, Y. Han, C. S. Lim, Y. Lu, J. Wang, J. Xu, H. Chen, C. Zhang, M. Hong and X. Liu, Nature, 2010, 463, 1061.

22 R. K. Sharma, A.-V. Mudring and P. Ghosh, J. Lumin., 2017, 189, 44.

23 X. Sun, Y.-W. Zhang, Y.-P. Du, Z.-G. Yan, R. Si, L.-P. You and C.-H. Yan, Chem.-Eur. J., 2007, 13, 2320.

24 S. N. Achary and A. K. Tyagi, Mater. Res. Bull., 2001, 36, 1441.

25 I. M. Ranieri, S. L. Baldochi and D. Klimm, J. Solid State Chem., 2008, 181, 1070.

26 P. Ptacek, H. Schäfer, K. Kömpe and M. Haase, Adv. Funct. Mater., 2007, 17, 3843.

27 D. Chen, P. Huang, Y. Yu, F. Huang, A. Yang and Y. Wang, Chem. Commun., 2011, 47, 5801.

28 Q. Zhang and Y. Bing, Chem. Commun., 2011, 47, 5867.

29 P. Ghosh and A. Patra, J. Phys. Chem. C, 2008, 112, 19823.

30 X. Zhai, S. Liu, Y. Zhang, G. Qin and W. Qin, J. Mater. Chem. C, 2014, 2, 2037.

31 A. Aebischer, M. Hostettler, J. Hauser, K. Krämer, T. Weber, H. U. Güdel and H.-B. Bürgi, Angew. Chem., Int. Ed., 2006, 45, 2802.

32 M. Wang, Q.-L. Huang, H.-X. Zhong, X.-T. Chen, Z.-L. Xue and X.-Z. You, Cryst. Growth Des., 2007, 7, 2106.

33 G. Xiang, J. Zhang, Z. Hao, X. Zhang, Y. Luo, S. Lü and H. Zhao, CrystEngComm, 2014, 16, 2499.

34 M. Pang, X. Zhai, J. Feng, S. Song, R. Deng, Z. Wang, S. Yao, X. Ge and H. Zhang, Dalton Trans., 2014, 43, 10202.

35 W. Zhang, F. Ding and Y. S. Chou, Adv. Mater., 2012, 24, OP236.

36 N. Niu, F. He, S. Huang, S. Gai, X. Zhang and P. Yang, RSC Adv., 2012, 2, 10337.

37 H.-X. Mai, Y.-W. Zhang, R. Si, Z.-G. Yan, L.-D. Sun, L.-P. You and C.-H. Yan, J. Am. Chem. Soc., 2006, 128, 6426.

38 Y. Liu, D. Tu, H. Zhu, R. Li, W. Luo and X. Chen, Adv. Mater., 2010, 22, 3266.

39 L. Wang, R. Yan, Z. Huo, L. Wang, J. Zeng, J. Bao, X. Wang, Q. Peng and Y. Li, Angew. Chem., Int. Ed., 2005, 44, 6054.

40 X. Chen, D. Peng, Q. Jua and F. Wang, Chem. Soc. Rev., 2015, 44, 1318.

41 G. Chen, H. Ågren, T. Y. Ohulchanskyy and P. N. Prasad, Chem. Soc. Rev., 2015, 44, 1680.

42 G.-S. Yi and G.-M. Chow, Chem. Mater., 2007, 19, 341.

43 A. Grzechnik, P. Bouvier, W. A. Crichton, L. Farina and J. Köhler, Solid State Sci., 2002, 4, 895.

44 D. Yang, Y. Dai, P. Ma, X. Kang, M. Shang, Z. Cheng, C. Li and J. Lin, J. Mater. Chem., 2012, 22, 20618.

45 Y. Zhang, X. Li, Z. Hou and J. Lin, Nanoscale, 2014, 6, 6763. 46 Y. Zhang, X. Li, X. Kang, Z. Hou and J. Lin, Phys. Chem. Chem. Phys., 2014, 16, 10779.

47 R. D. Shannon, Acta Crystallogr., Sect. A: Cryst. Phys., Diffr., Theor. Gen. Crystallogr., 1976, 32, 751. 
48 R. K. Sharma, Y. N. Chouryal, S. Chaudhari, J. Saravanakumar, S. R. Dey and P. Ghosh, ACS Appl. Mater. Interfaces, 2017, 9, 11651.

49 E. R. Parnham, A. M. Z. Slawin and R. E. Morris, J. Solid State Chem., 2007, 180, 49.

50 P. Ghosh and A.-V. Mudring, Nanoscale, 2016, 8, 8160.

51 G. K. Williamson and W. H. Hall, Acta Metall., 1953, 1, 22.

52 P. Ghosh and A. Patra, J. Phys. Chem. C, 2007, 111, 7004.
53 A. M. Smith, A. M. Mohs and S. Nie, Nat. Nanotechnol., 2009, 4, 56-63.

54 R. L. Penn and J. F. Banfield, Science, 1998, 281, 969.

55 R. L. Penn and J. F. Banfield, Am. Mineral., 1999, 84, 871.

56 B. R. Judd, Phys. Rev., 1962, 127, 750.

57 G. S. Ofelt, J. Chem. Phys., 1962, 37, 511.

58 P. Ghosh, A. Kar and A. Patra, Nanoscale, 2010, 2, 1196. 